\title{
PREPARA, CHEGOU A HORA DE SER PROFESSORA!
}

\author{
PREPARE, IT'S TIME TO BE TEACHER!
}

\author{
Fabiane de Andrade Leite ${ }^{1}$ \\ Franciele Siqueira Radetzke ${ }^{2}$
}

RESUMO: Apresenta-se neste texto um relato de vivências que se tornaram experiências docentes, possibilitadas pelas atividades realizadas durante o estágio curricular supervisionado de um curso de Licenciatura em uma Universidade pública. Destaca-se uma sequencia didática direcionada para o estudo das Ligações Químicas e o processo de constituição docente. O olhar para o processo formativo é analisado por meio das escritas reflexivas realizadas em diário de bordo, em que foram identificados(as) momentos/categorias de investigação: preparação, observação, reconstrução e constituição. Os momentos de formação permitem indiciar as vivências que se tornam experiências significativas no processo de formação do "ser professor".

Palavras-chave: Formação. Experiência. Constituição.

ABSTRACT: It is presented in this text an account of life that became teacher experiences, made possible by the activities carried out during the supervised curricular internship of a Licentiate degree course at a public university. It stands out a didactic sequence directed to the study of chemical bonds and the process of teacher constitution. The look at the formative process is analyzed through the reflective writings carried out in logbook, in which the moments / categories of investigation were identified: preparation, observation, reconstruction and constitution. The moments of formation allow us to point out the life situations that become significant experiences in the process of teacher training.

Keywords: Formation. Experience. Constitution.

\section{Primeiras palavras}

Um momento enriquecedor no processo de formação docente é, sem dúvida, o “experimentar” da profissão. Um período muito aguardado pelo futuro professor que é conflituoso, imprevisível, transformador e com intensa dimensão formativa, pois possibilita a vivência em sala de aula - o tecer de um processo de ensinar e aprender articulado às ações construídas no exercício da formação inicial. Nesta etapa, as perspectivas não se distanciam da sala de aula, pelo contrário, é para ela que se direcionam, agora com olhar ampliado no desafio de mediar conhecimentos, na hora e vez de "ser professor".

\footnotetext{
${ }^{1}$ Professora de Estágio e Práticas de Ensino nos Cursos da área de Ciências da Natureza da Universidade Federal da Fronteira Sul - Campus Cerro Largo/RS. Doutora em Educação nas Ciências. E-mail: fabianeleite@hotmail.com

${ }^{2}$ Licencianda do Curso de Química Licenciatura da Universidade Federal da Fronteira Sul - Campus Cerro Largo/RS. Bolsista do Programa de Educação Tutorial - PET Ciências. E-mail: francielesradetzke@gmail.com
} 
O processo de investigar a formação do "ser professor", que contemplamos nesta escrita, corresponde às ações teóricas e práticas realizadas no decorrer da formação inicial e que se efetivam em experiências significativas, conforme apresentado por Larrosa (2002, p. 25). Para o autor, "a experiência é aquilo que 'nos passa', ou que nos toca, ou que nos acontece, e ao nos passar, nos forma e nos transforma". Ainda, nos entendimentos do autor, a experiência vai sendo adquirida pelo sujeito na medida em que ele significa as ações e no modo como vai atribuindo sentidos à elas e, nessa direção, afirma que a experiência:

[...] requer um gesto de interrupção [...]: requer parar para pensar, parar para olhar, parar para escutar, pensar mais devagar, olhar mais devagar, e escutar mais devagar; parar para sentir, sentir mais devagar, demorar-se nos detalhes, suspender a opinião, suspender o juízo, suspender a vontade, suspender o automatismo da ação, cultivar a atenção e a delicadeza, abrir os olhos e os ouvidos, falar sobre o que nos acontece, aprender a lentidão, escutar aos outros, cultivar a arte do encontro, calar muito, ter paciência e dar-se tempo e espaço. (LARROSA, 2002, p. 25).

Com esse propósito, temos investido esforços em analisar vivências realizadas por futuros professores que se tornam experiências significativas no processo de formação docente. Assim, nossas intenções vão ao encontro do relatar vivências que são construídas em diálogos com sentimentos de formação e transformação, alcançados à medida que os acontecimentos em sala de aula transformam e formam o "ser professor". Momentos que requerem ser compartilhados, pois se tornam arte de constituir a identidade docente de forma autêntica e construtora da profissão.

Nesse sentido, buscamos compreender os momentos vivenciados antes, durante e após a realização do Estágio curricular supervisionado III: Ciências no ensino fundamental. O componente curricular acena para a integração entre teoria e prática por meio de vivências, experiências e mediação de conhecimentos adquiridos em um curso de licenciatura da área de Ciências da Natureza e suas Tecnologias de uma universidade pública do interior do estado do Rio Grande do Sul, com o objetivo de planejar, executar e analisar a prática docente de ensino em Ciências em sala de aula.

A vivência formativa foi realizada em uma escola do interior de um município da região das Missões no Rio Grande do Sul. Destacamos que, no processo de estágio realizado, foram dedicadas 126 horas/aula, sendo 52 horas de docência em sala de aula. As atividades foram realizadas no turno da tarde com turmas do oitavo e nono ano, contendo respectivamente, 15 e 11 estudantes.

Nessa direção, compreendemos que as práticas pedagógicas desenvolvidas em sala de aula pelo(a) futuro(a) professor(a) tornam-se significativas à formação docente dos acadêmicos 
de cursos de Licenciatura, ao possibilitarem o contato direto com o contexto profissional escolhido. As vivências no dia-a-dia da escola podem instigar os(as) futuros(as) professores(as) para a construção de novos olhares e perspectivas com a profissão e, assim, promover o início da construção de uma identidade de professor (a). Para tanto, como meio de resgatar as vivências e compreender quais os aspectos que contribuem para a formação de significativas experiências docentes, realizamos uma análise das reflexões desencadeadas/proporcionadas pelos momentos de docência exercidos, tendo em vista que:

[...] os professores desempenham um importante papel na produção e estruturação do conhecimento pedagógico porque refletem, de uma forma situada, na e sobre a interação que se gera entre o conhecimento científico [...] e a sua aquisição pelo aluno, refletem na e sobre a interação entre a pessoa do professor e a pessoa do aluno, entre a instituição escola e a sociedade em geral. Desta forma, têm um papel ativo na educação e não um papel meramente técnico que se reduza à execução de normas e receitas ou à aplicação de teorias exteriores à sua própria comunidade profissional. (ALARCÃO, 2005, p. 176).

Do mesmo modo, Schön (1992, p. 83) ressalta que "é possível olhar retrospectivamente e refletir sobre a ação-na-ação", ou seja, o professor pode recorrer várias vezes a uma mesma aula, pensar no que aconteceu, no que observou, no significado da aula e ainda em eventuais adaptações de outros sentidos. Além disso, destacamos o processo de formação, o qual vai além de uma única prática, mas de várias que convergem para um posicionamento reflexivo do "professor" em formação acerca de sua prática. Para Schön (1992), a reflexão na ação preconiza a reflexão sobre ações passadas, podendo essas se projetarem no futuro como novas práticas, possibilitando ao professor desenvolver novos raciocínios, novas formas de pensar, de compreender, de agir e equacionar problemas (FONTANA; FÁVERO, 2013).

Nessa direção, buscamos, no decorrer da escrita, ressaltar as reflexões realizadas em Diário de Bordo (DB), construído por uma licencianda, uma das autoras deste texto. O DB é um instrumento utilizado no processo formativo e segue a perspectiva de Porlán e Martin (1997). Os autores ressaltam que "o diário de bordo é usado como um guia para a reflexão sobre a prática, favorecendo ao professor a consciência sobre seu processo de evolução e sobre seus modelos de referência" (1997, p. 22). Desse modo, ao final de cada aula desenvolvida na escola, a licencianda recorria ao DB e nele refletia, anotava os pensamentos e as convicções acerca do delinear de suas ações e o posicionamento dos alunos nos processos de ensino e aprendizagem desenvolvidos.

Destacamos que as discussões estão direcionadas para as reflexões de uma sequencia didática relacionada ao estudo das ligações químicas, em que procuramos destacar o planejamento e as reflexões atinentes ao desenvolvimento, tendo em vista que ao findar das 
ações, em sala de aula, volta-se para as escritas com um direcionamento construtivo, ou seja, a observação de um tecer de concepções e reflexões que foram convergindo, formando, transformando e reconstruindo-se ao construir e constituir o posicionamento da licencianda, enquanto professora. Tais observações instigam ainda inquietações decorrentes do processo de constituição docente, do ambiente observado e dos diálogos compartilhados.

Desse modo, a escrita é norteada por dois momentos em especial, observados na leitura em DB, sendo eles: "Planejamento Inicial", em que se apresenta o processo com olhar voltado para as atividades que foram realizadas em sala de aula, para as práticas pedagógicas articuladas aos referenciais e ao conhecimento construído na graduação. Um segundo momento é: “O desenvolvimento: as experiências e diálogos compartilhados". Nessa parte, destacamos o delinear das vivências por meio de momentos de formação: preparação, observação, reconstrução e constituição. Os momentos evidenciam aspectos que contribuem para tornar as vivências em experiências significativas.

\section{Planejamento inicial}

Dentre as tarefas da docência temos o planejamento de ensino. Compreendemos que planejar as ações a serem realizadas em sala de aula não é apenas uma necessidade do trabalho do professor corresponde a uma organização intencional do que será realizado em sala de aula. Tal perspectiva se fortalece na defesa de que todo o trabalho realizado em sala de aula deve ter intencionalidades que contribuem para qualificar o processo de ensino e favorecer a aprendizagem. Ao realizar o planejamento de uma aula o professor reflete sobre as etapas essenciais do processo: os objetivos, o conteúdo, a metodologia e a avaliação (CASTRO; TUCUNDUVA; ARNS, 2008).

No contexto do estágio, foram planejadas 52 horas/aulas, organizadas em dois blocos (sequências didáticas) para o $9^{\circ}$ ano e três blocos para o $8^{\circ}$ ano. O planejamento foi compartilhado com a professora titular das turmas e os conceitos discutidos com o $9^{\circ}$ ano estavam relacionados ao átomo; tabela periódica; elemento químico e ligações químicas, os quais foram organizados em uma mesma sequencia didática e os conteúdos relacionados aos óxidos integraram um segundo bloco de aulas. Para o $8^{\circ}$ ano, os conteúdos dialogados estavam relacionados ao sistema digestório, sistema respiratório e sistema circulatório, cada qual compreendeu um bloco de planejamento diferenciado, mas não independente.

No processo de construção das metodologias articulamos conhecimentos e perspectivas compartilhadas durante a formação acadêmica, com vistas ao processo de significação conceitual, como meio de proporcionar aos alunos "o desenvolvimento de uma compreensão 
do mundo que lhes dê condições de continuamente colher e processar informações, desenvolver sua comunicação, avaliar situações, tomar decisões, ter atuação positiva e crítica em seu meio social" (BRASIL, 1998, p.62).

Aliado a isso, as sequencias metodológicas acenaram para perspectivas como o Educar pela Pesquisa (MORAES; GALIAZZI; RAMOS, 2002); uso da História da Ciência; filmes relacionados ao conteúdo; (re)contextualização de conhecimentos; experimentação; Histórias em Quadrinhos; escritas e reescritas entre outras metodologias, com olhar voltado para a construção de conhecimentos pelos alunos de forma significativa.

Entre as abordagens propomos a construção de um Caderno de Ciências pelos alunos, no qual registravam as compreensões e, ao longo dos diálogos compartilhados em sala de aula, iam reescrevendo-as com base nos entendimentos produzidos. A essa perspectiva atribui-se a ideia de (re)contextualização de conhecimentos, que direciona atenção às concepções iniciais dos alunos acerca de determinado conceito com olhar para as vivências, cuja significação conceitual vai sendo alcançada ao se atingir níveis mais elevados de generalização (VIGOTSKI, 2001).

Para Wenzel (2014, p. 82-83) “é preciso ampliar os espaços, na sala de aula, para ouvir os estudantes, seja pela fala, seja pela escrita, bem como, de desafiá-los a explicitar o seu entendimento". Nessa direção, a construção dos Cadernos de Ciências, foi acompanhada pela professora, tendo em vista os possíveis processos de mediação.

Figura 1. Caderno de Ciências utilizado nas aulas no Estágio Curricular Supervisionado III: Cíências no Ensino Fundamental

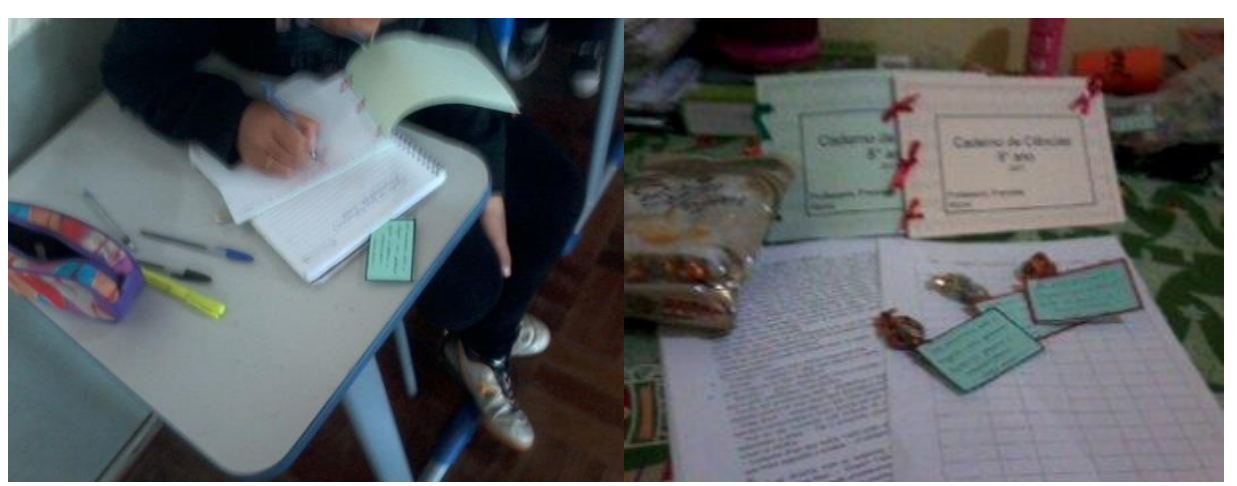

Fonte: Arquivo do pesquisador.

As dinâmicas de interação que permearam todas as aulas potencializaram a motivação e o interesse dos alunos para a participação nas atividades desenvolvidas. A intenção de focalizar o estudo de determinados conteúdos na participação dos alunos vai ao encontro do que salienta Vigotski (2001). De acordo com o autor, os processos de construção de 
conhecimentos são estabelecidos por meio da interação com os outros e com o meio, num processo sempre intencional e mediado pelo uso de instrumentos e signos. Dessa forma, promover/possibilitar a participação dos alunos na construção de suas aprendizagens possibilita ao professor potencializar os processos de ensino e aprendizagem e avançar na significação conceitual dos alunos ao passo que a articulação entre conhecimentos iniciais e conhecimentos científicos é fortalecida. Tal perspectiva amplia as discussões e sinaliza para a importância do processo de mediação, exercido pelo professor, ao estabelecer diálogos entre saberes e fazeres com olhar para a construção de conhecimentos de forma significativa.

Nessa direção, como atividades que promovem a interação entre alunos e entre aluno e professor, são destacadas nos blocos de aulas, atividades em grupo como jogos didáticos, construção de cartazes, resolução de exercícios de forma oral, leituras investigativas, construção de uma tabela periódica atentando-se para conceitos como propriedades, camada de valência, distribuição eletrônica, construção de uma pirâmide alimentar, atividades experimentais entre outras perspectivas.

Pensando na multiplicidade de ações e perspectivas apresentadas no planejamento das aulas, ressaltamos uma das sequencias didáticas desenvolvidas com o $9^{\circ}$ ano, que esteve relacionada ao conteúdo das Ligações Químicas. O delinear metodológico contemplou as perspectivas do Educar pela Pesquisa (MORAES; GALIAZZI; RAMOS, 2002) cuja proposta gira em torno dos três momentos: questionamento, construção de argumentos e comunicação. Dessa forma, no transcorrer dos diálogos observamos momentos de problematização, produção de argumentos direcionadas as problemáticas e para além delas, a comunicação de saberes construído por meio da fala e escrita.

O processo teve início com um vídeo contemplando aspectos da história da ciência e as perspectivas apresentadas por alguns filósofos gregos acerca de que o universo era formado pela combinação de 4 elementos. A utilização do vídeo teve como intenção potencializar discussões acerca dos aspectos históricos que contribuem para compreender de forma crítica o tema apresentado, possibilita o questionamento e o debate entre alunos e entre professor e aluno a respeito da construção de fatos científicos e concepções (SANTOS, 2011).

Os alunos foram instigados a pensar na possibilidade de o ar, terra, água e fogo serem elementos químicos. Na sequência, realizou-se a leitura de uma história em quadrinhos, intitulada “Associabilidade”, no livro Química Geral em Quadrinhos (PALHARES, 2008). As Histórias em Quadrinhos destacam-se pela forma diferenciada de comunicação visual e verbal direcionada aos conteúdos trabalhados, possibilitando o decorrer da leitura um olhar atento e investigativo. Nesse viés, 
[...] as histórias em quadrinhos podem ser utilizadas para introduzir um tema, para aprofundar um conceito já apresentado, para gerar discussão a respeito de um assunto, para ilustrar uma ideia. Não existem regras para sua utilização, porém, uma organização deverá existir para que haja um bom aproveitamento de seu uso no ensino podendo desta forma, atingir o objetivo da aprendizagem. (PALHARES, 2008, p. 4).

No sentido de problematizar os conceitos relacionados às ligações químicas, os alunos foram convidados a observar nos rótulos de embalagens a organização dos elementos, com vistas ao entendimento das ligações químicas sob um olhar inicial. Procurou-se discutir as propriedades dos gases nobres e a estabilidade adquirida pelos outros elementos quando associados a outros. É importante destacar, que todas as discussões aguçadas pelos alunos eram registradas em seus Cadernos de Ciências individualmente, mesmo que o diálogo ocorria no grande grupo.

No entanto, para além das inquietações iniciais, foram direcionados momentos para a construção argumentos direcionados as problematizações, ou seja, argumentos que "justifiquem as novas posições assumidas" (MORAES; GALIAZZI; RAMOS, 2002, p. 8). Nesse viés duas atividades metodológicas merecem destaque, entre elas o uso da experimentação, tendo em vista que as atividades experimentais se mostram promissoras ao possibilitar o diálogo entre teoria e prática, além da participação dos alunos e da mediação no processo de produção de conhecimentos.

Quando os alunos interagem com os fenômenos decorrentes do experimento, "ficam-lhes abertas, as portas para as mais diversas interpretações e conclusões” (PACHECO, 1996, p. 71) e desse modo não se pode limitar o experimento a determinadas interpretações e conclusões pré-estipuladas, mas sim dar a oportunidade de os alunos pensarem e desenvolverem sua autonomia. Isso contribui para que os processos de mediação em sala de aula, de fato se efetivem direcionando-se para o desenvolvimento humano e social dos alunos, num movimento de ir e vir no processo de (re)significação conceitual.

Foi realizado o teste da condutividade elétrica em diversas substâncias, há exemplo o sal de cozinha (sólido e dissolvido), parafina de vela e colher de metal. Em meio às discussões, os tipos de ligação química (iônica, covalente e metálica) eram ressaltadas, haja vista as observações, tudo era anotado e após os alunos precisavam apresentar explicações para tais fenômenos. Ainda, como meio de potencializar as discussões relacionadas aos tipos de ligações químicas, realizou-se também a atividade experimental intitulada Martelando Materiais, a proposta esteve ancorada no artigo Martelando materiais e ressignificando o ensino de ligações químicas (ARIZ; MACHADO, 2011). Tal prática possibilita problematizar a atenção dos alunos para um nível microscópico, ao instigá-los acerca do que acontece quando uma força é 
exercida sobre as substâncias ( $\mathrm{NaCl}$, parafina e metal). Para tanto, com o auxílio de um martelo, os alunos pressionaram com força em cada uma das situações. Por exemplo, ao se bater com o martelo em um cristal iônico ele vai se espedaçar, isso acontece porque a força aplicada empurra os átomos de cargas iguais para se juntarem, no entanto eles se repelem e acabam quebrando o cristal. Se bater com o martelo em um metal ele não se quebra, só amassa. Isso acontece porque o mar de elétrons protege os cátions uns dos outros. E na vela quando exercida a força as moléculas ainda continuam sendo parcialmente atraídas, por isso uma parte quebra e a outra amassa (ARIZ; MACHADO, 2011).

No entanto, somente a construção de argumentos não é suficiente (MORAES; GALIAZZI; RAMOS, 2002). Segundo os autores,

[...] é importante que a pesquisa em sala de aula atinja um estágio de comunicar resultados, de compartilhar novas compreensões, de manifestar novo estado do ser, do fazer e do conhecer, o que contribui para sua validação na comunidade que esse processo está se dando. (MORAES; GALIAZZI; RAMOS, 2002, p. 9).

Dessa forma, como meio de acompanhar a compreensão dos alunos acerca da construção de seus conhecimentos, além das escritas no Caderno de Ciências, realizou-se uma atividade de montagem de modelos de compostos iônicos e moleculares utilizando bolas de isopor e palitos, em que os alunos, em grupos, analisaram a montagem e, após, discutiu-se na turma a explicação do tipo de ligação envolvida e algumas propriedades, como compartilhamento e transferência de elétrons, tamanho dos átomos entre outras.

A seguir, destaco as experiências significadas nos momentos de constituição do "ser professor".

\section{0 desenvolvimento: as experiências e diálogos compartilhados}

Nessa parte, o olhar direciona-se para as reflexões destacadas em DB, cujo objetivo volta-se para o percurso formativo, na vez e posição de professor com vistas às atividades planejadas e agora já desenvolvidas. Para tanto, recortes das escritas realizadas em DB tomam parte e direcionam a discussão.

Os momentos apresentados vão ao encontro do que é proposto por Schön (1992) ao destacar que o conhecimento prático é constituído na reflexão na ação e na reflexão sobre a reflexão na ação, pois o professor constrói sua profissionalização ao examinar, interpretar e avaliar suas atividades. Com esse propósito, acenamos para quatro momentos que contribuíram para que as vivências realizadas se tornassem experiências docentes, no sentido apresentado por Larrosa (2002). Como primeiro momento, destacamos a Preparação. Nesta etapa, 
identificamos aspectos significativos da formação acadêmica que perpassam o momento de estágio, como o sentimento de ser professor pela primeira vez em uma sala de aula:

[...] é chegada a hora de entrar em sala de aula, e reconhecer esse momento, como um desafio: o de fazer florir toda constituição que construí, por meio de diálogos compartilhados na Universidade, encontros de formação, aprendizagens compartilhadas, práticas pedagógicas e sem dúvida por meio da pesquisa. Um momento inicial. Senti medo, ansiedade, emoções! Quando entrei em sala de aula, o Ser Professor tomou-me por completo. Senti-me dona daquele espaço (a sala de aula). (DB, 28 de Agosto, 2017).

No excerto, a licencianda reporta ao reconhecimento da acadêmica com relação a sua opção profissional. Ela se identifica no espaço de sala de aula, agora como Professora e, para tanto, justifica esse momento como um desafio atrelado ao processo de mediação de conhecimentos de forma significativa. Ainda, destacamos a importância atribuída aos diálogos compartilhados, um aspecto que fortalece a sua vivência formativa e possibilitou que o momento de estágio se tornasse uma experiência significativa.

Como segundo momento formativo, identificamos a construção do olhar de professor, a Observação. Como o convívio e diálogo com a turma é algo novo, o medo e a ansiedade foram motivos de destaques. Nas escritas identificamos um cuidadoso olhar da licencianda com a realidade vivenciada:

[...] o $9^{\circ}$ é uma turma mais tranquila, eu diria, mais calma. Já o $8^{\circ}$ ano é uma turma agitada, curiosa, é preciso ser precisa com eles para o trabalho/ planejamento da aula manter-se organizado. São dois espaços bem distintos, mas com potencial para um grande trabalho, assim acredito. (DB, 28 de Agosto, 2017).

Ao andar da trajetória da Professora em formação inicial, destacamos que ela vai realizando melhor suas escolhas, no entendimento de que intervenções são necessárias. As colocações são referenciadas logo nas primeiras aulas, com relação ao $8^{\circ}$ ano,

[...] a turma é bem inquieta, querem saber de tudo, menos do conteúdo. Assim, preciso ser bem organizada, não posso abrir espaço, pois a turma se dispersa e outros comentários aquém do conteúdo tomam conta dos diálogos. [...] os alunos tinham dificuldade, estavam preocupados com seus erros. Enfatizei que essa não era a questão central da atividade e sim as suas aprendizagens, conhecer melhor suas concepções e reconstruí-las. (DB, 31 de Agosto, 2017).

Dessa forma, o primeiro desafio salientado pela acadêmica, encontra-se em fazer com que os alunos observem a importância de suas aprendizagens, fato ainda distanciado, pois os alunos "têm muita preocupação em procurar logo a resposta e copiá-la, outras perspectivas para eles não é interessante" (DB, 31 de Agosto, 2017). A estagiária continua as aulas direcionando as situações metodológicas para a participação e envolvimento dos alunos 
abarcando a (re) contextualização dos conhecimentos, história da Ciência, dinâmicas de interação, entre outras propostas. No entanto, na terceira semana, observa-se a necessidade de uma busca de novos olhares pela estagiária, ao dialogar sobre o $9^{\circ}$ ano, e é aí que observamos o terceiro momento, o processo de Reconstrução.

Penso que os alunos possuem dificuldades na compreensão dos conceitos, é uma turma bastante silenciosa. Preciso rever propostas metodológicas que envolvam mais os alunos e que desenvolvam a participação dos alunos de forma prazerosa. A tranquilidade da turma observada na primeira aula começa a me inquietar, preciso que participem mais, sinto essa necessidade, preciso senti-los durante o processo... (DB, 11 de Setembro, 2017).

E assim, a turma que no primeiro dia de aula fez com que a estagiária se sentisse aflita pela agitação, começa a tranquilizá-la, pois tornaram-se participativos, o que contribui no processo de construção de conhecimentos. A intenção de focalizar o estudo de determinados conteúdos na participação dos alunos vai ao encontro do que salienta Vigotski (2001), ao enfatizar que os processos de construção de conhecimentos são estabelecidos por meio da interação com os outros e com o meio, num processo sempre intencional e mediado pelo uso de instrumentos e signos.

Dessa forma, prover a participação dos alunos na construção de suas aprendizagens possibilita ao professor potencializar a tomada de consciência dos alunos para com suas compreensões anteriores e a partir daí avançar em outros níveis de significação (WENZEL, 2014). Assim, o uso de dinâmicas de interação entre os alunos e entre professor e aluno são destacadas como meio de motivar e despertar o interesse dos alunos pela aprendizagem, sendo para tanto "necessário o uso de uma linguagem atraente, capaz de aproximá-lo o máximo possível da realidade, transformando os conteúdos em vivência” (FIALHO, 2008, p.1). A intenção de potencializar a participação dos alunos no processo de aprender é destacada pela estagiária, que se sente incomodada em buscar metodologias diferenciadas, disposta a rever sua prática.

No percurso formativo, a estagiária vai percebendo a desmotivação dos alunos, mesmo com aulas dinâmicas, e sente-se incomodada com isso:

[...] percebi no andamento da aula que os alunos não estavam motivados. Em seus olhares percebia um desânimo, um dizer de porque estudar Química? [...] Aqueles olhares e aquelas palavras iam me incomodando, no entanto precisava mostrar firmeza. Incomodavam porque eu pensava na importância da condução do trabalho que eu estava realizando, não eram conceitos isolados que ressaltava, trazia para o tecer da significação dos conceitos as justificativas que permeavam determinadas compreensões sempre acenado para a história da Ciência. (DB, 14 de Setembro, 2017). 
A futura professora permanece com foco no processo de significação conceitual por meio de práticas pedagógicas que instigam a participação dos alunos, a construção de argumentos por meio da fala e a escrita. Destacamos que os pressupostos da formação são mantidos e, nesse momento, acena-se ao quarto momento de formação, o da Constituição:

[...] preciso instigar os alunos a buscar conhecimentos, a se interessarem pelas temáticas, é preciso inovar. Minhas expectativas afloram a cada passo da realização desse estágio. O qual se mostra fundamental na compreensão de minha constituição profissional e de minha prática. [...] o descaso pelos estudos, me levam a pensar no que Vigotski ressaltou ao dizer que o aluno para significar conceitos precisa de uma necessidade, sem tal não há motivação para o aprendizado. Mas como motivar meus alunos?? É o que me pergunto a cada dia! Compreendo a dificuldade e nível de abstração para alguns conceitos, mas preciso fazer com que eles participem mais e mais, é preciso que signifiquem conceitos. (DB, 18 de Setembro, 2017).

É importante destacar que a necessidade de busca por inquietações, relacionadas à significação conceitual, potencializam a constituição profissional da estagiária, pois: "ao sair da aula não paro de pensar em diferentes metodologias que contribuam para acelerar o processo de significação conceitual. Preciso pesquisar, investigar, escrever, refletir, reviver minha prática” (BD, 25 de Setembro, 2017).

Em suma, a sequência didática relacionada às ligações químicas, ressalta um recorte dos aspectos metodológicos utilizados pela futura professora, e que durante o período de docência foram marcantes em sua constituição, tendo em vista que a possibilidade de desenvolver tais práticas ainda lhe deixa inquieta, ao afirmar que,

[...] as estratégias metodológicas por mim utilizadas, a exemplo da sequencia didática das ligações químicas, possibilitam o envolvimento do aluno para o processo de ensino e aprendizagem. Os alunos querem participar, a aula tornase mais agradável, mas ao mesmo tempo que isso acontece, é preciso buscar a importância de determinados fenômenos. E é ai que nasce uma das minhas mais importantes instigações. Faltou tempo para que eu trabalhasse essa outra parte e talvez por isso que me 'dói' saber que está chegando o final. No entanto o caminho começou a ser trilhado, é preciso continuar, repensar, me fazer sim A Professora que busco a cada passo construir. (DB, 2017).

Nessa direção, possibilitar a participação dos alunos, a contextualização dos conhecimentos trabalhados, prática da escrita e retomada de suas compreensões é o caminho, no entanto é preciso investir mais em situações que promovam a significação conceitual, é preciso dialogar interesses com os alunos e fortalecer o que de fato faça sentido a eles. Dessa forma o professor estará contribuindo à formação de cidadãos críticos e comprometidos para com a sociedade em que vivemos. 
Diante de tais colocações, reitera-se a importância do direcionamento metodológico para o desenvolvimento das aulas, no entanto destaca-se o real sentido da profissão docente, na hora e vez de "ser professor". Não há 'receita' pronta e acabada, e sim desafios a serem dialogados a cada passo. É necessário criar e inovar, direcionando-se para a construção e significação conceitual dos alunos.

Tal perspectiva é identificada no processo de formação da licencianda que se coloca comprometida com o desafio, reconstruindo suas ações a cada momento único da profissão, num diálogo entre saberes, fazeres e questionamentos.

Assim, destacamos que as vivências compartilhadas e que foram refletidas no DB da licencianda se tornaram experiências, marcas profundas de um processo de formação, transformação permanente. As reflexões ora destacadas contribuíram para que as vivências se tornassem experiências significativas da docência. Um processo que acenou para aspectos marcantes e recorrentes de uma prática pedagógica: o de se preparar, parar e observar, andar mais um pouquinho, sentir, experimentar e reconstruir certezas na arte e desafio de constituirse Professor e de formar cidadãos.

\section{Considerações finais}

Investigar a prática docente é sem dúvida um exercício a ser realizado continuamente, tanto em processos de formação inicial como continuada de professores. Momentos e vivências necessitam ser dialogados, em busca de ações que tocam o sujeito e sua formação, haja vista da construção de um sujeito crítico e comprometido com seus fazeres.

A intenção de problematizar a sequencia didática relacionada às ligações químicas, objetivou investigar as situações metodológicas propostas e, após o desenvolvimento, acenar para os momentos de formação que contribuíram para que vivências fossem significadas em processo de formação/constituição. Tal direcionamento mostrou-se importante no processo de formação da acadêmica, pois vários aspectos puderam ser evidenciados e mostraram-se atinentes ao propósito de analisar um processo de formação.

Momentos que marcam a constituição da futura professora foram evidenciados: preparação, observação, reconstrução e constituição. Tais momentos colocam-se como complementares ao processo de formação inicial, ao passo que indiciam ações de sentimentos que tocam a construção do "ser professor", e ao tocá-lo o transformam.

\section{REFERÊNCIAS}

ALARCÃO, I. Formação reflexiva de professores: estratégias de supervisão. Porto: Porto Editora, 2005. 
CASTRO, P. A. P. P de; TUCUNDUVA, C. C.; ARNS, E. M. A importância do planejamento das aulas para organização do trabalho do professor em sua prática docente. Revista Athena, v. 10, n. 10, jan./jun. 2008

FIGURA 1. Caderno de Ciências utilizado nas aulas no Estágio Curricular Supervisionado III: Ciências no Ensino Fundamental. Fotografias dos autores. 2017.

FONTANA, M.J.; FÁVERO, A.A. Professor reflexivo: uma integração entre teoria e prática. Revista de Educação do IDEAU, Caxias do Sul, v. 8, n. 17, jan/jun. 2013.

LARROSA, J. B. Notas sobre a experiência e o saber de experiência. Revista Brasileira de Educação, São Paulo, n. 19, jan/fev/mar/abr. 2002.

MORAES, R; GALIAZZI, M.C; RAMOS, M. G. Pesquisa em sala de aula: fundamentos e pressupostos. In: MORAES, R; LIMA, V. M. R. Pesquisa em sala de aula: tendências para a educação em novos tempos. Porto Alegre: EDIPUCRS, 2002. P. 4-9.

PACHECO, D. Um problema no ensino de ciências: organização conceitual do estudo dos fenômenos. Educação e Filosofia, 10 (19) p. 63-81, jan/jun, 1996.

PALHARES, M.C. História em quadrinhos: uma ferramenta pedagógica para o ensino de história. Dia a Dia Educação, Paraná, 2008. Disponível em:

<http://www.diaadiaeducacao.pr.gov.br/portals/pde/arquivos/2262-8.pdf> Acesso em: 15 out. 2017.

PARIZ, E.; MACHADO, P.F.L. Martelando materiais e ressignificando o ensino de ligações químicas. In: Encontro Nacional de Ensino e Pesquisa em Ciências (ENPEC), Anais, 2011, São Paulo.

PORLÁN, R.; MARTÍN, J. El diario del profesor. Sevilla: Díada Editora, 1997.

SANTOS, E. G. A história da ciência no cinema: contribuições para a problematização da concepção de natureza da ciência. 2011. 124 f. Dissertação (Mestrado em Ensino Científico e Tecnológico). Programa de Pós-Graduação em Ensino Científico e Tecnológico. Universidade Regional Integrada do Alto Uruguai e das Missões. Disponível em: <http://www.urisan.tche.br/admin/upload/eliane.pdf > Acesso em: 14 out. 2017.

SCALABRIN, I. C.; MOLINARI, A. M. C. A importância da prática do estágio supervisionado nas licenciaturas. Revista UNAR, Araras, v. 7, n. 1, mar. 2013.

SCHÖN, D. A. Formar professores como profissionais reflexivos. In: NÓVOA, A. Os professores e a sua formação. Lisboa, Dom Quixote, 1992.

VIGOTSKI, L. S. A construção do pensamento e da linguagem. Trad. Paulo Bezerra, 1. Ed. São Paulo: Martins Fontes, 2001.

WENZEL, J. S. A escrita em processos interativos: (re)significando conceitos e a prática pedagógica em aulas de química. Curitiba: Appris, 2014.

Relato recebido em: 14/02/2018

Relato aceito em: 07/05/2018 